\title{
Therapeutic Concentrations of Mitoxantrone Elicit Energetic Imbalance in H9c2 Cells as an Earlier Event
}

\author{
Luciana Grazziotin Rossato • Vera Marisa Costa • \\ Vânia Vilas-Boas • Maria de Lourdes Bastos • \\ Anabela Rolo $\cdot$ Carlos Palmeira $\cdot$ Fernando Remião
}

Published online: 18 September 2013

(c) Springer Science+Business Media New York 2013
Abstract Mitoxantrone (MTX) is a chemotherapeutic agent that emerged as an alternative to anthracycline ther- apy. However, MTX also causes late cardiotoxicity, being oxidative stress and mitochondrial-impaired function pro- posed as possible mechanisms. This work aimed to inves- tigate the relevance of these mechanisms to the MTX toxicity in $\mathrm{H} 9 \mathrm{c} 2$ cells, using therapeutic concentrations. The observed cytotoxicity of MTX was time and concentration dependent in both lactate dehydrogenase leakage assay and MTT reduction assay. Two therapeutic concentrations (100 $\mathrm{nM}$ and $1 \mu \mathrm{M})$ and three time points were selected (24, 48, and $96 \mathrm{~h}$ ) for further studies. Both MTX concentrations caused a significant increase in caspase- 3 activity, which was not prevented by inhibiting MTX CYP450-metabolism. Significant decreases were observed in the total and reduced glutathione levels only in MTX $100 \mathrm{nM}$ at $96 \mathrm{~h}$; however, neither alterations in oxidized glutathione nor increases in the malondialdehyde levels were observed at any time or concentrations tested. On the other hand, changes in the intracellular ATP levels, mitochondrial membrane poten- tial, and intracellular calcium levels were observed in both concentrations and all time tested. Noteworthy, decreased
L. G. Rossato $(\square) \cdot$ V. M. Costa · V. Vilas-Boas ·
M. de Lourdes Bastos · F. Remião ( $\square)$
REQUIMTE, Laboratório de Toxicologia, Departamento de Ciências Biológicas, Faculdade de Farmácia, Universidade do Porto, Rua Jorge Viterbo Ferreira, 228, 4050-313 Porto, Portugal e-mail: luciana.g.rossato@gmail.com
F. Remião
e-mail: remiao@ff.up.pt
A. Rolo · C. Palmeira
Departamento de Ciências da Vida, Centro de Neurociências
e Biologia Celular de Coimbra, Universidade de Coimbra,
Coimbra, Portugal
levels of ATP-synthase expression and activity and increases in the reactive species generation were observed at $96 \mathrm{~h}$ in both working concentrations. However, the rad- ical scavenger $N$-acetylcysteine or the mitochondrial func- tion enhancer $L$-carnitine did not prevent MTX cytotoxicity. Thus, this work evidenced the early MTX-induced ener- getic crisis as a possible key factor in the cell injury.
Keywords Mitoxantrone - Cardiotoxicity · Energetic failure - Oxidative stress $\cdot$ Energetic imbalance

$\begin{array}{ll}\text { Abbreviations } \\ \text { DCFH-DA } & \text { Dichlorodihydrofluorescein diacetate } \\ \text { DHR } & \text { Dihydrorhodamine 123 } \\ \text { DMEM } & \text { Dulbecco's modified eagle's medium } \\ \text { DMSO } & \text { Dimethyl sulfoxide } \\ \text { DTNB } & \text { 5,5-Dithio-bis(2-nitrobenzoic) acid } \\ \text { FBS } & \text { Fetal bovine serum } \\ \text { FI } & \text { Fluorescence intensity } \\ \text { GSH } & \text { Reduced glutathione } \\ \text { GSHt } & \text { Total glutathione } \\ \text { i.p } & \text { Intraperitoneal } \\ \text { GSSG } & \text { Oxidized glutathione } \\ \text { LDH } & \text { Lactate dehydrogenase } \\ \text { MTT } & \text { 3-(4,5-Dimethylthiazol-2-yl)-2,5- } \\ & \text { diphenyltetrazolium bromide } \\ \text { MTX } & \text { Mitoxantrone } \\ \text { NAC } & N \text {-acetylcysteine } \\ \beta-N A D H & \text { Reduced } \beta \text {-nicotinamide adenine } \\ & \text { dinucleotide } \\ \text { Pi } & \text { Inorganic phosphate } \\ \text { SD } & \text { Standard deviation } \\ \text { TBA } & \text { Thiobarbituric acid } \\ \text { TMRM } & \text { Tetramethylrhodamine }\end{array}$




\section{Introduction}

Mitoxantrone (MTX) is an anthracenedione chemotherapeutic agent used in the treatment of solid tumors, such as breast and prostate cancer, and hematological malignances, namely acute leukemia and lymphoma [1]. Due to its immunosuppressive properties, MTX has been also employed in the treatment of multiple sclerosis [2]. MTX acts as an intercalating agent being a powerful inhibitor of DNA and RNA synthesis, and affects the cell cycle at various stages [3]. Moreover, MTX is an inhibitor of topoisomerase II [1], and, recently, the MTX potential epigenetic effects were demonstrated given its high affinity to bind to histone $\mathrm{H} 1$ and core histones in vitro [4].

Due to their similar chemical structure and anticancer mechanisms, MTX was considered an alternative to anthracycline chemotherapy with the advantage of allowing the administration of lower relative doses than doxorubicin [5]. However, it became evident after its clinical use that MTX also promoted late irreversible cardiotoxicity in up to $18 \%$ of treated patients, which sometimes is clinically diagnosed several years after treatment [1]. Furthermore, this risk is increased with higher cumulative doses [1]. MTX is extensively distributed and accumulates in heart tissue. In fact, MTX is still detected in the human heart $(716 \mathrm{ng} / \mathrm{g}$ wet weight) 35 days after a single dose $\left(12 \mathrm{mg} / \mathrm{m}^{2}\right)$ [6], showing that cardiac cells maintain a prolonged contact after MTX administration.

The observed heart failure promoted by MTX is clinically similar to that caused by doxorubicin [1]; however, mechanistic studies of MTX-induced cardiotoxicity are scarce on the available literature. The cardiac side effects promoted by doxorubicin have been extensively related to oxidative stress [7] and to mitochondrial-impaired function [8]. Studies demonstrated that the oxidoreductive metabolism of MTX produces reactive intermediates $[9,10]$ and that MTX shows particular effectiveness against tumors expressing high content of heme-peroxidases [11], suggesting the involvement of reactive species in its successful antitumor action. Additionally, its cytotoxicity has already been prevented by the inhibition of CYP450-mediated metabolism in human hepatoma-derived cell line [10, 12], in isolated adult rat hepatocytes [12], and in MCF-7 human breast cancer cells [13]. In fact, recently, our research group highlighted that the bioactivation of MTX may also be involved in its undesirable cardiac side effects since the cytotoxicity of MTX was partially prevented in a cardiomyoblast H9c2 cell model by inhibiting CYP450- and CYP2E1-mediated metabolism [14].

Energetic imbalance was suggested to be a consequence of MTX treatment. In cultured neonatal rat heart cells, the $3 \mathrm{~h}$ incubation with MTX (about 0.1-10 $\mu \mathrm{M}$ ) caused a concentration-dependent decline in the ATP levels after $72 \mathrm{~h}$
[15]. Mitochondrial swelling was observed after electron and light microscopy in hearts excised from female BALB/c mice killed 1 week after treatment with MTX $(0.2 \mathrm{mg} / \mathrm{kg})$, intraperitoneal (i.p.), weekly, for 12-week [5]. Furthermore, cardiac mitochondria isolated from rats treated with MTX $(1 \mathrm{mg} / \mathrm{kg}$ i.p.), twice a week, for 4 weeks, showed a reduction in the electron transfer and the respiratory chain activity and uncoupling of oxidative phosphorylation [16]. In spite of these 3 studies, the mitochondrial role on MTX-induced cardiotoxicity and the mechanisms involved are still poorly understood due to the lack of focused studies on their functionality while facing MTX.

This work aimed to evaluate the mechanisms involved in the MTX cardiotoxicity using the H9c2 cells as cellular model exposed to therapeutic concentrations of this drug. $\mathrm{H} 9 \mathrm{c} 2$ is a cell line derived from rat heart, that is considered a valuable model to assess in vitro cardiotoxicity [17], specially due to its metabolic features, which are comparable to those found in rat heart [18]. The work used this in vitro model to evaluate several mitochondrial and mitochondrial-related pathways, namely ATP levels, mitochondrial membrane potential, or ATP-synthase activity or expression. Other cellular components, which could be related to mitochondrial functionality, namely calcium levels, formazan metabolization, reactive species generation, or glutathione levels were also evaluated. The use of a CYP450 inhibitor (metyrapone), a CYP2E1 inhibitor (diallyl sulfide), a reactive species scavenger $(N$ acetylcysteine $[\mathrm{NAC}]$ ), and a mitochondrial function enhancer ( $L$-carnitine) was also performed to evaluate the role of the respective pathways in MTX cytotoxicity.

\section{Methods}

\section{Chemicals}

All chemicals and reagents were of analytical grade or of the highest grade available. MTX hydrochloride, NAC, $L$-carnitine, reduced glutathione (GSH), oxidized glutathione (GSSG), glutathione reductase (GR, EC 1.6.4.2), 2-vinylpyridine, reduced $\beta$-nicotinamide adenine dinucleotide $(\beta$ -

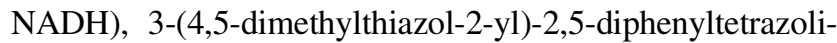
um bromide (MTT), 5,5-dithio-bis(2-nitrobenzoic) acid (DTNB), the caspase-3 substrate ( $N$-Acetyl-Asp-Glu-ValAsp $p$-nitroanilide), dihydrorhodamine 123 (DHR), luciferin, luciferase, thiobarbituric acid (TBA), protease inhibitors cocktail, anti-goat actin monoclonal antibody, and antirabbit ATP-synthase polyclonal antibody were obtained from Sigma-Aldrich (St. Louis, MO). Dichlorodihydrofluorescein diacetate (DCFH-DA), tetramethylrhodamine (TMRM), and Fluo-3 AM were obtained from Molecular Probes (Eugene, OR). Dimethyl sulfoxide (DMSO) and 
perchloric acid $\left(\mathrm{HClO}_{4}\right)$ were obtained from Merck (Darmstadt, Germany). The nitrocellulose membranes (Hybond ECL), ECL chemiluminescence detection reagents, the anti-rabbit and anti-goat IgG peroxidase secondary antibody were obtained from GE Healthcare (Buckinghamshine, UK). Flow cytometry reagents (BD Facs-Flow ${ }^{\mathrm{TM}}$ and FacsClean $^{\mathrm{TM}}$ ) were purchased from Becton, Dickinson, and Company (São Jose, CA). Bio-Rad DC protein assay kit was purchased from Bio-Rad laboratories (Hercules, CA).

Dulbecco's modified eagle's medium (DMEM) with 4,500 $\mathrm{mg} / \mathrm{L}$ glucose and GlutaMAX ${ }^{\mathrm{TM}}$, fetal bovine serum (FBS), trypsin $(0.25 \%)$-EDTA $(1 \mathrm{mM})$, and antibiotic $(10,000 \mathrm{U} / \mathrm{ml}$ penicillin, $10,000 \mathrm{~g} / \mathrm{ml}$ streptomycin) were obtained from Gibco Laboratories (Lenexa, KS).

\section{H9c2 Cell Culture}

The H9c2 cell line was a generous gift from Dr. Vilma Sardão, Center for Neurosciences and Cellular Biology, University of Coimbra, Portugal. Cells were cultured in DMEM supplemented with $10 \% \mathrm{FBS}, 100 \mathrm{U} / \mathrm{ml}$ of penicillin, and $100 \mathrm{U} / \mathrm{ml}$ of streptomycin in $75 \mathrm{~cm}^{2}$ tissue culture flasks at $37{ }^{\circ} \mathrm{C}$ in a humidified $5 \% \mathrm{CO}_{2}-95 \%$ air atmosphere. Cells were fed every 2-3 days, and sub-cultured once they reached $70-80 \%$ confluence. After seeding, cells were allowed to grow for 2 days, and then, the medium was replaced to start the treatments.

\section{Cytotoxicity Assays}

Cells were seeded at a density of 35,000 cells $/ \mathrm{ml}$ in 48 -well plates (final volume of $250 \mu \mathrm{l}$; about $8,000 \mathrm{cells} / \mathrm{cm}^{2}$ ), as previously described [14]. Concentration-response and time-response curves of MTX were performed using incubation times of $24,48,72$, and $96 \mathrm{~h}$ with MTX concentration range of $10 \mathrm{nM}$ to $100 \mu \mathrm{M}(10,100 \mathrm{nM}, 1,5$, $10,50$, and $100 \mu \mathrm{M})$. Cellular damage was quantitatively assessed through the measurement of LDH release [19] and also through the MTT reduction assay [14], as previously described. For the following experiments, MTX working concentrations selected were $100 \mathrm{nM}$ and $1 \mu \mathrm{M}$ based on cytotoxicity test results.

Studies were also performed by co-incubating for $96 \mathrm{~h}$ MTX with potential protective agents, the reactive species scavenger and GSH precursor NAC (1 mM) [20], and the energetic function enhancer $L$-carnitine $(1 \mathrm{mM})$ [21].

\section{Caspase-3 Activity Assay}

Caspase-3 activity was determined in H9c2 cells after $100 \mathrm{nM}$ or $1 \mu \mathrm{M}$ MTX incubation. The incubation period was defined after pilot studies at 6,24, and $96 \mathrm{~h}$ incubation period and chosen to be $24 \mathrm{~h}$. The CYP450 inhibitor metyrapone $(0.5 \mathrm{mM})$ and the CYP2E1 inhibitor diallyl sulfide $(150 \mu \mathrm{M})$ were used as possible counteracting agents to the activation of caspase- 3 caused by MTX [14]. Cells were seeded at a density of 35,000 cells $/ \mathrm{ml}$ in 6-well plates (final volume of $2.5 \mathrm{ml}$, about 9,000 cells/ $/ \mathrm{cm}^{2}$ ) and allowed to grow for 2 days. The medium was replaced and cells were incubated with MTX $(100 \mathrm{nM}$ or $1 \mu \mathrm{M})$, in the presence or absence of each metabolism inhibitor, 2 wells per condition. After $24 \mathrm{~h}$ incubation, cells were detached and collected to tubes ( 2 wells for one tube). Cells were centrifuged at $210 \times g$ for $5 \mathrm{~min}$, at $4{ }^{\circ} \mathrm{C}$, and the supernatant was discarded. One hundred and fifty microliters of lysis buffer (50 mM HEPES, $0.1 \mathrm{mM}$ EDTA, $0.1 \%$ CHAPS, $1 \mathrm{mM}$ DTT) was added to the pellets. After complete lysis, samples were centrifuged at $16,000 \times g$, for $10 \mathrm{~min}$, at $4{ }^{\circ} \mathrm{C}$. The supernatant, which contains the cytoplasmatic fraction, was collected to another tube. All steps were performed on ice. Caspase-3 activity was determined at $405 \mathrm{~nm}$ in a multi-well plate reader (BioTech Instruments, Vermont, US) as previously described [19].

The protein content in the cell lysate was quantified using the Bio-Rad DC protein assay kit as described by the manufacturer, and albumin solutions were used as standards.

\section{Evaluation of Oxidative Stress}

\section{Evaluation of Reactive Species Generation}

Cells were seeded at a density of 35,000 cells $/ \mathrm{ml}$ in 48 -well plates (final volume of $250 \mu \mathrm{l}$, about $8,000 \mathrm{cells} / \mathrm{cm}^{2}$ ) and allowed to grow for 2 days.

In order to assess the early reactive species generation, the medium was replaced and cells were incubated with two different probes, DHR (final concentration $100 \mu \mathrm{M}$ ) [19] or DCFH-DA (final concentration $10 \mu \mathrm{M}$ ) as previously described [22], for $30 \mathrm{~min}$ at $37^{\circ} \mathrm{C}$ and in the dark. After washing cells twice with phosphate-buffered saline in order to remove non-internalized probes, the new medium was placed and cells were incubated with MTX (100 nM and $1 \mu \mathrm{M}) . \mathrm{H}_{2} \mathrm{O}_{2}(150 \mu \mathrm{M})$ was used as a positive control for the probes [22]. Cells were kept in the dark at $37^{\circ} \mathrm{C}$. The detection and quantification of intracellular reactive species was performed using a fluorescence plate reader (baseline $485 \mathrm{~nm}$ excitation, $528 \mathrm{~nm}$ emission), every hour, until $10 \mathrm{~h}$ incubation.

In order to evaluate the late generation of reactive species, cells were first incubated with MTX (100 nM and $1 \mu \mathrm{M})$. After $96 \mathrm{~h}$ incubation at $37{ }^{\circ} \mathrm{C}$, the medium was replaced and cells were incubated with DCFH-DA $(10 \mu \mathrm{M})$, for $30 \mathrm{~min}$, at $37^{\circ} \mathrm{C}$, in the dark. At the end of incubation period, the medium was replaced and the detection was performed as described above. 
Measurement of Intracellular Total Glutathione (GSHt), GSH, and GSSG Levels

Cells were seeded at a density of 35,000 cells $/ \mathrm{ml}$ in $55 \mathrm{~cm}^{2}$ Petri dishes (final volume of $12.5 \mathrm{ml}$, about 8,000 cell $/ \mathrm{cm}^{2}$ ). After growing for 2 days, the medium was replaced and MTX (100 $\mathrm{nM}$ and $1 \mu \mathrm{M})$ was added. After a 24,48 , and $96 \mathrm{~h}$ incubation period, the intracellular levels of GSHt and GSSG in the H9c2 cells were evaluated by the DTNB-GSSG reductase recycling assay, as previously described [20].

The protein content was assayed by the Lowry method, using albumin solutions as standards, as previously described [20]. GSHt, GSH, and GSSG contents were normalized to total protein content, and the final results were expressed as nmol of GSH or GSSG per mg of protein.

\section{Evaluation of Lipid Peroxidation}

Cells were seeded at a density of 35,000 cells $/ \mathrm{ml}$ in 6-well plates (final volume of $2.5 \mathrm{ml}$, about 9,000 cells $/ \mathrm{cm}^{2}$ ). After growing for 2 days, the medium was replaced for fresh medium and MTX $(100 \mathrm{nM}$ and $1 \mu \mathrm{M})$ was added. Each condition (control, MTX $100 \mathrm{nM}$, or MTX $1 \mu \mathrm{M}$ ) was performed in duplicate. After 24,48 , or $96 \mathrm{~h}$ incubation at $37{ }^{\circ} \mathrm{C}$, the medium was removed and cells of two wells were collected with phosphate-buffered saline, $\mathrm{pH}=7.4$, on ice to the same centrifuge tube. Cells were centrifuged $\left(210 \times g, 5 \mathrm{~min}, 4^{\circ} \mathrm{C}\right)$ and the supernatant was removed. The obtained pellet of cells was lysed with $100 \mu \mathrm{l}$ of $5 \% \mathrm{HClO}_{4}$, homogenized, and centrifuged $\left(16,000 \times g, 10 \mathrm{~min}, 4{ }^{\circ} \mathrm{C}\right)$. Lipid peroxidation was assessed by measuring malondialdehyde in the supernatant fraction through a HPLC/UV method previously described [23], with some adaptations. The pellet was dissolved in $100 \mu \mathrm{l}$ $\mathrm{NaOH} 0.3 \mathrm{M}$, and the protein levels were determined by Lowry method, using albumin solutions as standards.

The HPLC analysis was carried out on a system consisting of a Gilson equipped with UV-VIS detection $(\lambda=532 \mathrm{~nm})$. Chromatographic separation was achieved using a Waters C18 Spherisorb $5 \mu$ M ODS2 $4.6 \times 250 \mathrm{~mm}$ column. The mobile phase consisted in $50 \mathrm{mM}$ ammonium acetate $(\mathrm{pH}=5.5)$ : methanol $(1: 1)+0.1 \%$ triethylamine. The flow rate was maintained isocratically at $0.6 \mathrm{ml} / \mathrm{min}$, and the total run time was $8 \mathrm{~min}$.

\section{Evaluation of the Energetic Function}

\section{Measurement of Intracellular ATP Levels}

Cells were seeded and allowed to grow following the same protocol used for the measurement of glutathione levels. Conversely, the cells were scrapped and treated with the same protocol described for the evaluation of glutathione levels (detailed above). ATP intracellular levels were measured as previously described [24].

\section{Evaluation of the ATP-synthase Expression}

For the in vitro assessment of the ATP-synthase expression, cells were seeded at a density of 35,000 cells $/ \mathrm{ml}$ in Petri dishes (final volume of $12.5 \mathrm{ml}$, about $8,000 \mathrm{cell} / \mathrm{cm}^{2}$ ). After growing for 2 days, the medium was replaced and MTX $(100 \mathrm{nM}$ and $1 \mu \mathrm{M})$ was added. After the incubation periods of 24,48 , and $96 \mathrm{~h}$ at $37^{\circ} \mathrm{C}$, cells were collected with phosphate-buffered saline, $\mathrm{pH}=7.4$, and centrifuged $\left(210 \times g, 5 \mathrm{~min}, 4^{\circ} \mathrm{C}\right)$. The supernatant was discarded and the pellet was lysed with RIPA buffer $[50 \mathrm{mMTris}-\mathrm{HCl}$, $150 \mathrm{Mm} \mathrm{NaCl}, 1 \%$ Igepal CA $630(\mathrm{v} / \mathrm{v}), 0.5 \%$ sodium deoxycholate $(\mathrm{w} / \mathrm{v})$, and $0.1 \% \operatorname{SDS}(\mathrm{w} / \mathrm{v}), \mathrm{pH}=7.4]$ supplemented with protease inhibitors cocktail. The ATPsynthase expression was evaluated through western immunoblot. Equal amounts of protein (quantified using the BioRad DC protein assay kit) were loaded and electrophoresed on $10 \%$ SDS-polyacrylamide gel and transferred to polyvinylidenedifluoride membrane. Membranes were blocked with $5 \%$ non-fat milk and incubated with the ATP-synthase antibody (1:500), overnight at $4{ }^{\circ} \mathrm{C}$. Actin (1:500) was used as loading control. The bands obtained through western blot were quantified with QuantityOne ${ }^{\circledR}$ software (Bio-Rad).

\section{Evaluation of the ATP-synthase Activity}

The activity of ATP-synthase was indirectly determined by analysis of the inorganic phosphate (Pi) released from ATP hydrolysis. Cells were seeded at a density of 35,000 cells/ $\mathrm{ml}$ in Petri dishes (final volume of $12.5 \mathrm{ml}$, about $8,000 \mathrm{cell} / \mathrm{cm}^{2}$ ). Cells were allowed to grow for 2 days, the medium was replaced, and MTX $(100 \mathrm{nM}$ and $1 \mu \mathrm{M})$ was added. Cells were incubated for $96 \mathrm{~h}$ at $37{ }^{\circ} \mathrm{C}$.

After the incubation period, cells were scrapped and treated with the same protocol described for the evaluation of ATP-synthase expression (detailed above). The ATPsynthase activity was determined in the cell lysate using $0.75 \mathrm{mg}$ protein (quantified using the Bio-Rad DC protein assay kit). The cell lysates were incubated with $2 \mathrm{ml}$ reaction medium $(125 \mathrm{mM}$ sucrose, $65 \mathrm{mM} \mathrm{KCl}, 2.5 \mathrm{mM}$ $\mathrm{MgCl}_{2}, 50 \mathrm{mM}$ HEPES, pH 7.4), at $37{ }^{\circ} \mathrm{C}$. Each condition (control, MTX $100 \mathrm{nM}$ or MTX $1 \mu \mathrm{M}$ ) was performed in two independent tubes, one of them in the presence of $2 \mu \mathrm{l}$ of $1 \mathrm{mg} / \mathrm{ml}$ oligomycin (inhibitor of mitochondrial ATPsynthase). The reaction was started with the addition of $50 \mu \mathrm{l}$ of $100 \mathrm{mM}$ ATP and was stopped with the addition of $1 \mathrm{ml} 40 \%$ trichloroacetic acid. Then, $1 \mathrm{ml}$ of the product of this reaction was incubated with $2 \mathrm{ml}$ of freshly prepared ammonium molybdate reagent containing ferrous 
sulfate and $2 \mathrm{ml}$ distillated water, for $5 \mathrm{~min}$. ATP-synthase activity is quantified subtracting the difference between the $\mathrm{Pi}$ released by ATP hydrolysis in the presence and absence of oligomycin. A standard curve of $\mathrm{Pi}$ was performed using $\mathrm{KH}_{2} \mathrm{PO}_{4}$. The absorbance of the reaction was measured at $665 \mathrm{~nm}$, and the results were expressed as $\mathrm{nmol} \mathrm{Pi} / \mathrm{mg} / \mathrm{min}$.

\section{Flow Cytometry Analysis}

Intracellular calcium and the evaluation of the mitochondrial membrane potential were determined through flow cytometry using the Fluo-3 AM and TMRM fluorescent probes, respectively. Cells were seeded at a density of 35,000 cells $/ \mathrm{ml}$ in 6-well plates (final volume of $2.5 \mathrm{ml}$, about 9,000 cells $/ \mathrm{cm}^{2}$ ). After growing for 2 days, the medium was replaced and MTX (100 nM and $1 \mu \mathrm{M})$ was added ( 3 wells per condition).

Fluorescence measurements of the cell suspensions were taken with a flow cytometer (FACSCalibur, Becton Dickinson Biosciences) equipped with a 488-nm argon ions laser. The green fluorescence of Fluo-3 AM was measured through a 530-nm band-pass filter (FL1), and the red fluorescence of TMRM was measured through a 575-nm band-pass filter (FL2). Acquisition data for 15,000 cells were gated to include only viable cells based on their forward and side light scatters and the propidium iodide ( $5 \mu \mathrm{g} / \mathrm{ml}$ ) incorporation. Logarithmic fluorescence was recorded and analyzed by the BDIS CellQuest Pro software (Becton Dickinson Biosciences). Non-labeled cells (with or without MTX) were analyzed in FL1 and FL2 in order to detect a possible contribution from cells autofluorescence to the analyzed fluorescence signals. Results were presented as mean fluorescence intensity (FI).

\section{Assessment of the Mitochondrial Membrane Potential}

After 24, 48, and $96 \mathrm{~h}$ incubation, the medium was removed and cells were washed with phosphate-buffered saline, $\mathrm{pH} 7.4$, and tripsinized with $0.25 \%$ trypsin/ $1 \mathrm{mM}$ EDTA in order to obtain a cell suspension. Cells were centrifuged $(250 \times g, 5 \mathrm{~min})$, the supernatant was discarded, and cells were suspended in $50 \mu$ culture medium containing $20 \mathrm{nM}$ TMRM [25]. Cells were incubated for $30 \mathrm{~min}$, at $37^{\circ} \mathrm{C}$, in the dark. After that, cells were washed twice with phosphate-buffered saline, $\mathrm{pH} 7.4$, centrifuged $(210 \times g, 5 \mathrm{~min})$, and kept on ice until flow cytometry analysis.

\section{Assessment of the Intracellular Calcium Levels}

The collection and preparation of the cells was done as in the assessment of the mitochondrial membrane potential (see above). The assessment of the intracellular calcium levels was performed as previously described [26].

\section{Statistical Analysis}

Results are presented as means \pm the standard deviation (SD) from independent experiments. Statistical comparisons between groups were performed with one-way ANOVA (in case of normal distribution) or Kruskal-Wallis test (one-way ANOVA on ranks-in case distribution is not normal). Significance was accepted at $p$ values $<0.05$. Details of statistical analysis are found in the legend of the figures.

\section{Results}

Low Concentrations of MTX Elicit Cytotoxic Effects in a Time- and Concentration-Dependent Manner

The cytotoxicity of MTX was demonstrated at different concentrations and time points, through the decline in the cell viability observed in the LDH leakage assay (Fig. 1) and through the decrease in the MTT reduction activity (Fig. 2). The cytotoxic effects observed in these two assays were dependent on MTX concentration and time of incubation, as shown in the Figs. 1 and 2 (time-response and concentration-response curves).

The decrease in the cell viability in observed the LDH leakage assay is related to cell rupture, and results are shown in the Fig. 1. After $24 \mathrm{~h}$ incubation, the lower concentrations tested $(10 \mathrm{nM}, 100 \mathrm{nM}$, and $1 \mu \mathrm{M})$ did not cause significant decreases in the cell viability compared to control. However, the $24 \mathrm{~h}$ incubation with 5 and $10 \mu \mathrm{M}$ MTX caused a significant decrease in cellular integrity, which was more notorious for the highest concentrations tested, namely 50 and $100 \mu \mathrm{M}$ MTX. After $48 \mathrm{~h}$, only the incubation with $10 \mathrm{nM}$ MTX did not decrease cell viability compared to control cells. The $48 \mathrm{~h}$ incubation with $100 \mathrm{nM}, 1,5,10,50$, and $100 \mu \mathrm{M}$ caused significant decreases in cell viability. After $72 \mathrm{~h}$ incubation, the cytotoxicity observed with the $10,100 \mathrm{nM}$, and $1 \mu \mathrm{M}$ MTX remained similar to the control values. The $72 \mathrm{~h}$ incubation with the other concentrations $(5,10,50$, and $100 \mu \mathrm{M})$ caused significant decreases in the cell viability. The cytotoxicity of MTX was even more evident in the longest incubation period $(96 \mathrm{~h})$. Ten nM MTX did not change cell viability compared to control; however, slight decreases were observed with the incubation with $100 \mathrm{nM}$ and $1 \mu \mathrm{M}$ MTX, and dramatic effects were observed with the higher concentrations of 5,10 , and $50 \mu \mathrm{M}$.

The reduction of MTT leads to the formation of formazan crystals, mostly by the action of mitochondrial 
Fig. 1 Effect of different concentrations of MTX on the H9c2 viability after $24 \mathrm{~h}(\mathbf{a})$, $48 \mathrm{~h} \mathrm{(b),} 72 \mathrm{~h}(\mathbf{c})$, and $96 \mathrm{~h}$

(d) of incubation at $37{ }^{\circ} \mathrm{C}$ evaluated by the LDH leakage assay. Results are presented as means $(\%) \pm \mathrm{SD}(n=24$ per condition out of 4 independent experiments) $(* * * p<0.001$ vs. Control). Statistical

comparisons were made using one-way ANOVA test followed by the Bonferroni post hoc test

Fig. 2 Effect of different concentrations of MTX after $24 \mathrm{~h} \mathrm{(a),} 48 \mathrm{~h} \mathrm{(b),} 72 \mathrm{~h}$ (c), and $96 \mathrm{~h}$ (d) incubation at $37{ }^{\circ} \mathrm{C}$ with $\mathrm{H} 9 \mathrm{c} 2$ cells evaluated by the MTT reduction activity assay. Results are presented as means $(\%) \pm \mathrm{SD}(n=18$ per condition out of 3 independent experiments). Statistical comparisons were made using one-way ANOVA test $(* * * p<0.001$ vs. Control) followed by the Bonferroni post hoc test
(A)

$24 \mathrm{~h}$

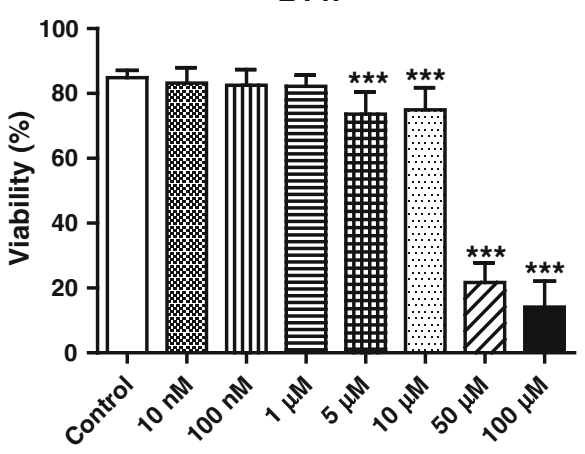

Mitoxantrone concentration

(C)

$72 \mathrm{~h}$

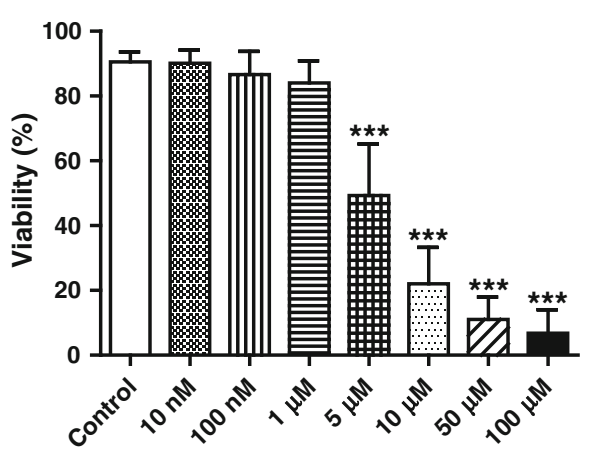

Mitoxantrone concentration

(A)

$24 \mathrm{~h}$

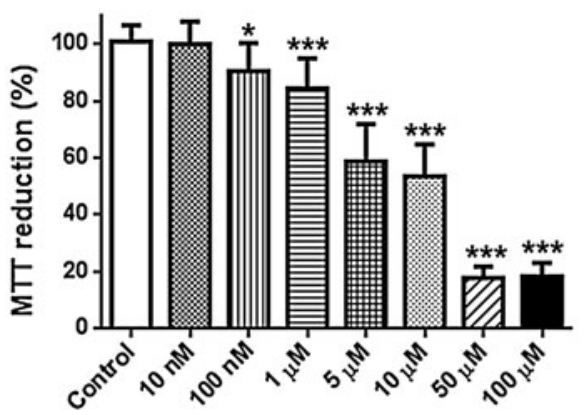

Mitoxantrone concentration

(C)

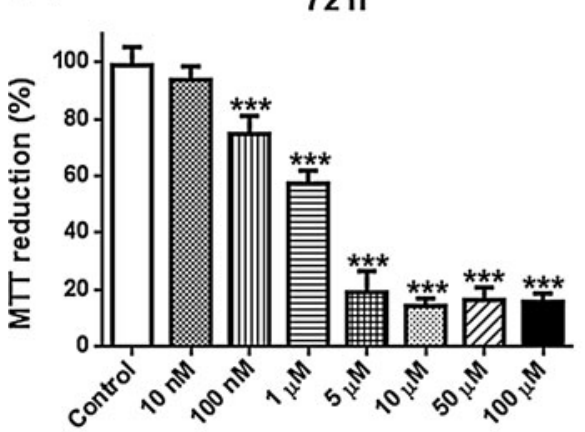

Mitoxantrone concentration
(B)

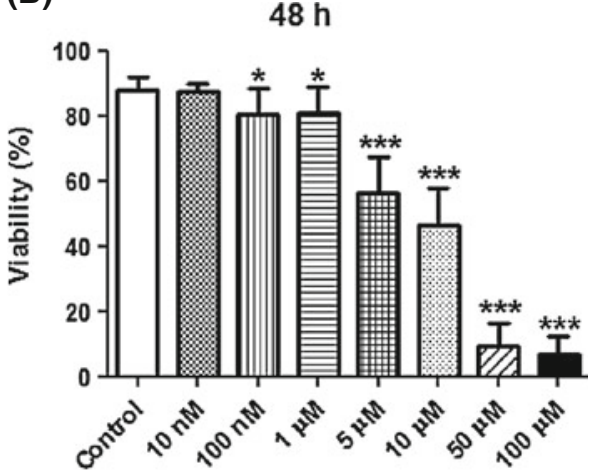

Mitoxantrone concentration

(D)

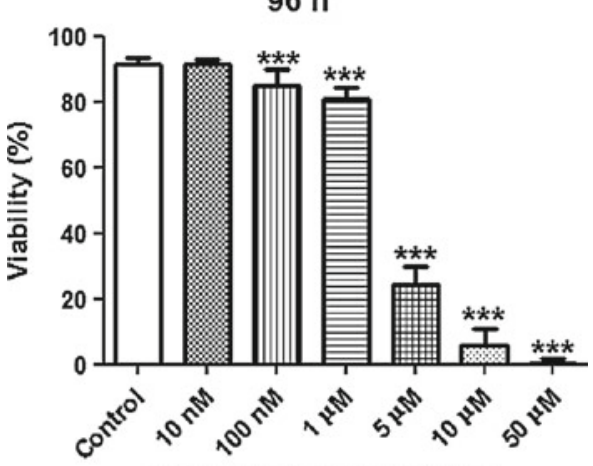

Mitoxantrone concentration

(B)

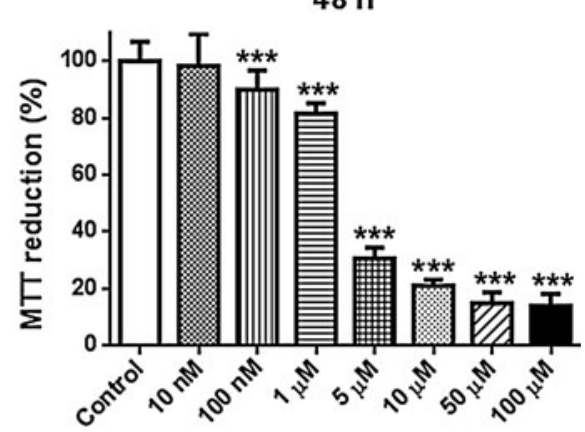

Mitoxantrone concentration

(D)

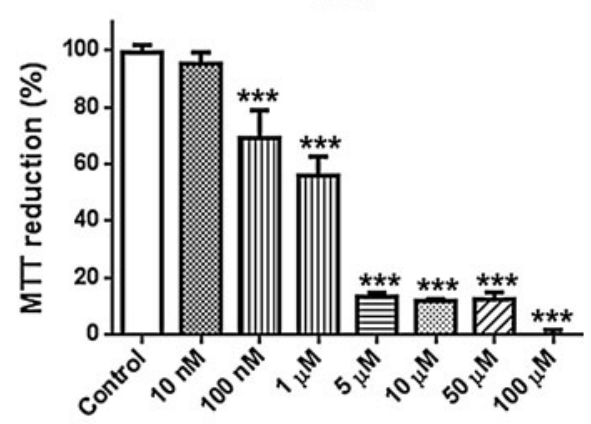

Mitoxantrone concentration 
dehydrogenases, thereby can be used as a mitochondrial viability index. After $24 \mathrm{~h}$, the \%MTT reduction observed in the $10 \mathrm{nM}$ MTX incubation was similar to control values. The incubation with $100 \mathrm{nM}$ or $1 \mu \mathrm{M}$ MTX caused slight, but significant, decreases in the \%MTT reduction. More pronounced cytotoxic effects were observed with the $24 \mathrm{~h}$ MTX incubation at 5, 10, 50, and $100 \mu \mathrm{M}$ concentrations. After $48 \mathrm{~h}$ incubation, the \%MTT reduction values in the $10 \mathrm{nM}$ MTX concentration remained similar to that in the control cells. MTX $100 \mathrm{nM}$ and $1 \mu \mathrm{M}$ caused slight significant decreases. Again, more notorious cytotoxic effects were observed with the higher concentrations of 5, 10, 50, and $100 \mu \mathrm{M}$. After $72 \mathrm{~h}$ incubation, the \%MTT reduction values observed with $10 \mathrm{nM}$ were similar to the control values. The $72 \mathrm{~h}$ incubations with higher concentrations $(100 \mathrm{nM}$, $1,5,10,50$, and $100 \mu \mathrm{M})$ caused significant decreases in $\%$ MTT reduction. Similar to what was observed in the LDH leakage assay, the cytotoxicity observed by MTT assay was time dependent being the cytotoxicity higher with the longest incubation period $(96 \mathrm{~h})$. The incubation with $10 \mathrm{nM}$ MTX did not cause any significant changes in the \%MTT reduction compared to control. The co-incubation with the radical scavenger NAC $(1 \mathrm{mM})$ or the mitochondrial function enhancer $L$-carnitine $(1 \mathrm{mM}) \mathrm{did}$ not prevent the cytotoxic effects observed with the incubation of MTX (100 nM and $1 \mu \mathrm{M})$ for $96 \mathrm{~h}$ in the reduction of MTT test (data not shown).

MTX Incubation Elicits an Increase in the Caspase-3 Activity After $24 \mathrm{~h}$

As can be observed in the Fig. 3, the incubation of $100 \mathrm{nM}$ and $1 \mu \mathrm{M}$ MTX, for $24 \mathrm{~h}$, at $37^{\circ} \mathrm{C}$, caused an increase in

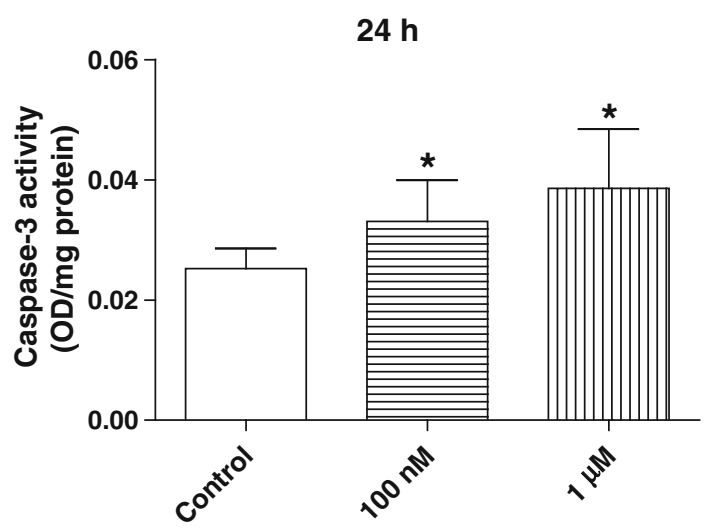

Fig. 3 Levels of caspase- 3 activity in the H9c2 cells after $24 \mathrm{~h}$ incubation with MTX $(100 \mathrm{nM}$ and $1 \mu \mathrm{M})$. Results are presented as mean $\pm \mathrm{SD}$ ( $n=6$ independent experiments). Statistical comparisons were made using Kruskal-Wallis test followed by the StudentNewman-Keuls post hoc test $\left({ }^{*} p<0.05\right.$ vs. Control) caspase- 3 activity $(0.033 \pm 0.007 \mathrm{OD} / \mathrm{mg}$ protein and $0.039 \pm 0.010 \mathrm{OD} / \mathrm{mg}$ protein, respectively), compared to control cells $(0.025 \pm 0.003 \mathrm{OD} / \mathrm{mg}$ protein $)$. The coincubation of MTX (in the same concentrations) with the CYP450 inhibitor metyrapone $(0.5 \mathrm{mM})$ or with the CYP2E1 inhibitor diallyl sulfide $(150 \mu \mathrm{M})$ did not prevent the observed effects in the caspase-3 assay (data not shown).

Reactive Species Generation and GSH Depletion after 96 h: No GSSG Formation or Lipid Peroxidation

The effect of MTX in the generation of reactive species was assessed using two different fluorescent probes, DCFH-DA $(10 \mu \mathrm{M})$ and DHR $(100 \mu \mathrm{M})$. In all the early time points tested $(1,2,3,4,5,6,7,8,9$, or $10 \mathrm{~h})$, no changes in intracellular reactive species generation with any of MTX-tested concentrations (100 nM and $1 \mu \mathrm{M})$ were observed (data not shown). However, as evidenced in the Fig. 4a), incubations with DCFH-DA after $96 \mathrm{~h}$ preincubation with MTX in both working concentrations caused a significant increase in the generation of reactive species $(137 \pm 46.7 \%$ in the MTX $100 \mathrm{nM}$ group and $141 \pm 56.9 \%$ in the MTX $1 \mu \mathrm{M}$ group compared to $100 \pm 10.3 \%$ in the control group).

No changes in the GSHt, GSH, and GSSG intracellular levels after the 24 and $48 \mathrm{~h}$ incubations with MTX (100 nM and $1 \mu \mathrm{M}$ ) were observed (data not shown). Only when cells were incubated with MTX (100 nM) for $96 \mathrm{~h}$, a significant decrease was observed in GSHt and GSH intracellular levels when compared with control group, as shown in Fig. 4b and c, respectively. No differences were found in GSSG levels in the previous conditions (data not shown). No significant changes were observed with the concentration of MTX $1 \mu \mathrm{M}$ for GSH, GSHt, or GSSG intracellular levels (data not shown).

No significant changes were observed in the malondialdehyde levels after incubation with MTX (100 nM and $1 \mu \mathrm{M})$ at any time point tested $(24,48$, or $96 \mathrm{~h})$ in comparison with control levels (data not shown).

MTX-Induced Energetic Impairment and Increased Levels of Intracellular Calcium at All Time Points

ATP intracellular levels after MTX incubation were assessed through the bioluminescence test. Significant decreases in the ATP levels were observed in all time point tested, as shown in the Fig. 5: after $24 \mathrm{~h}$ incubation with MTX (100 $\mathrm{nM}$ and $1 \mu \mathrm{M})$, the ATP intracellular levels were about $0.63 \pm 0.48 \mathrm{nmol} / \mathrm{mg}$ protein and $0.87 \pm 0.50 \mathrm{nmol} / \mathrm{mg}$ protein, respectively, compared to $1.77 \pm 0.49 \mathrm{nmol} / \mathrm{mg}$ protein for the control group. At the end of $48 \mathrm{~h}$ incubation, ATP levels were $1.23 \pm 0.37 \mathrm{nmol} / \mathrm{mg}$ protein in the MTX 
(A)

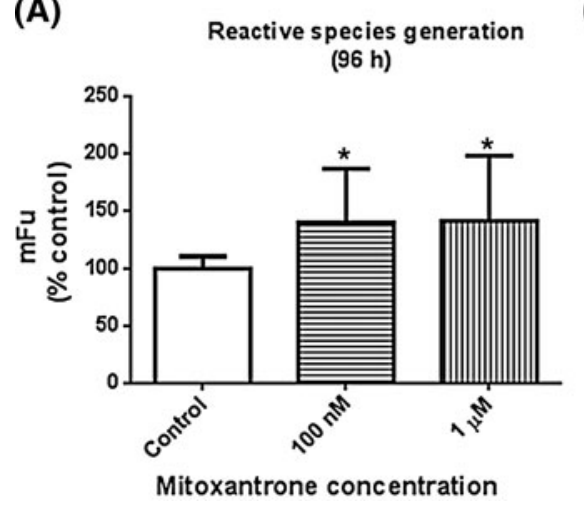

(B)

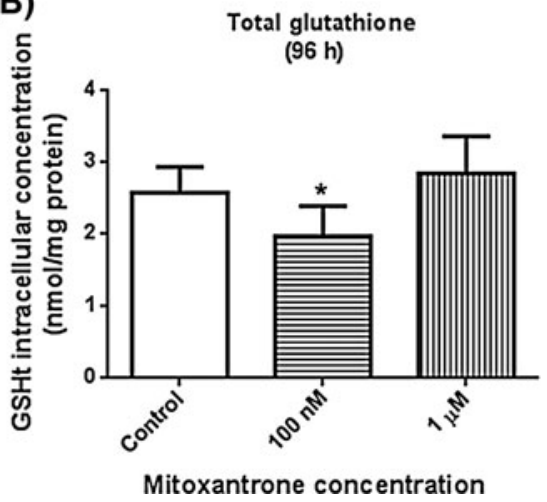

(C)

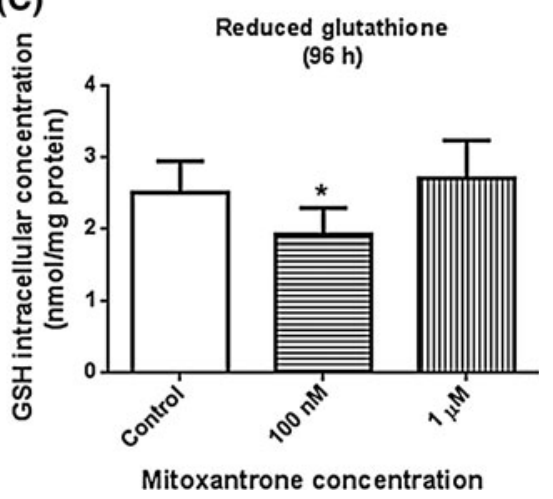

Fig. 4 Markers of oxidative stress after MTX incubation with H9c2 cells. a Intracellular levels of reactive species detected after incubation with DCFH-DA $(10 \mu \mathrm{M})$ fluorescent probe after $96 \mathrm{~h}$ pre-incubation with MTX $(100 \mathrm{nM}$ and $1 \mu \mathrm{M})$. Results are presented as means $(\%) \pm \mathrm{SD}$ ( $n=6$ independent experiments). Intracellular levels of b GSHt and c GSH after $96 \mathrm{~h}$ incubation with MTX $(100 \mathrm{nM}$ and $1 \mu \mathrm{M})$. Results are presented as mean $\pm \mathrm{SD}(n=7$ independent experiments). Statistical comparisons were made using Kruskal-Wallis test followed by the Student-Newman-Keuls post hoc test $(* p<0.05$ vs. Control)
(A)

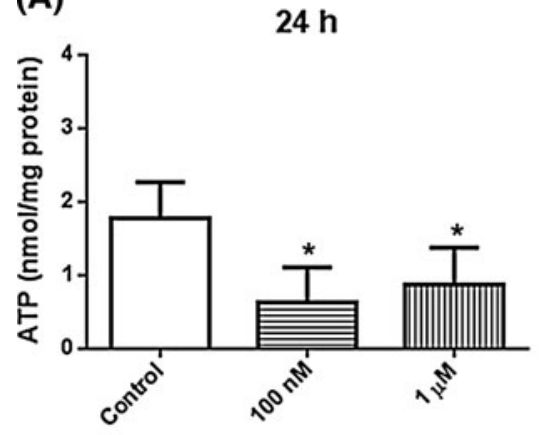

Mitoxantrone concentration
(B)

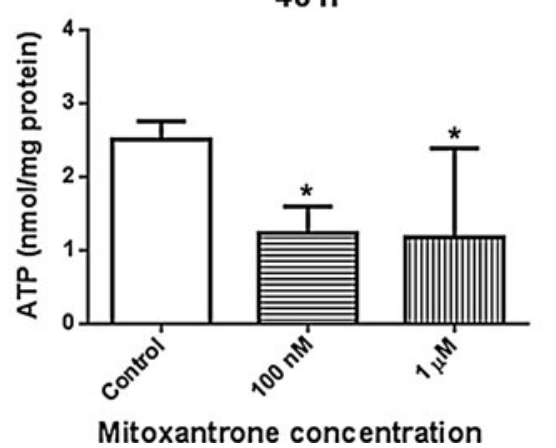

(C)

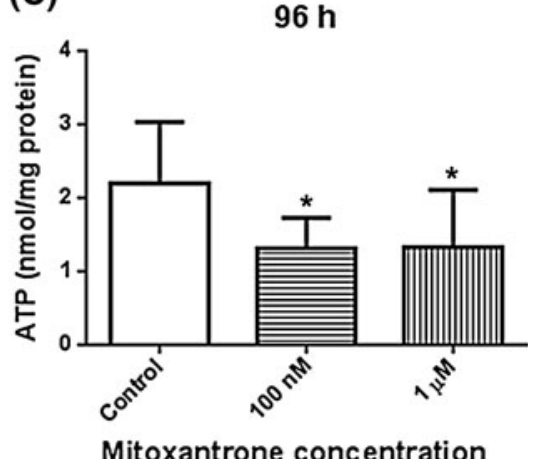

Fig. 5 ATP intracellular levels after MTX (100 nM and $1 \mu \mathrm{M})$ incubation for a $24 \mathrm{~h}, \mathbf{b} 48 \mathrm{~h}$, and $\mathbf{c} 96 \mathrm{~h}$. Results are presented as mean $\pm \mathrm{SD} \quad(n=5 \quad$ independent experiments). Statistical

$100 \mathrm{nM}$ group and $1.18 \pm 1.21 \mathrm{nmol} / \mathrm{mg}$ protein in the MTX $1 \mu \mathrm{M}$ group versus $2.50 \pm 0.25 \mathrm{nmol} / \mathrm{mg}$ protein for the control group. After $96 \mathrm{~h}$ incubation with MTX (100 nM and $1 \mu \mathrm{M})$, the ATP intracellular levels were about $1.31 \pm 0.42 \mathrm{nmol} / \mathrm{mg}$ protein and $1.33 \pm 0.78 \mathrm{nmol} / \mathrm{mg}$ protein, respectively, compared to $2.20 \pm 0.83 \mathrm{nmol} / \mathrm{mg}$ protein for the control group.

The expression of ATP-synthase was evaluated through western immunoblotting in all time points $(24,48$, and $96 \mathrm{~h}$ ), after incubation with MTX in both working concentrations. Results were normalized to the actin content and were expressed as the optic density ratio between ATPsynthase/actin (\% relative to the control). No significant changes were observed after 24 or $48 \mathrm{~h}$ incubation (data not shown). In contrast, after the $96 \mathrm{~h}$ incubation, significant decrease in the ATP-synthase expression was observed in both treated groups, as evidenced in Fig. 6a, b. The expression of ATP-synthase was about $86 \pm 3.1 \%$ in the MTX $100 \mathrm{nM}$ group, $84 \pm 3.6 \%$ in the MTX $1 \mu \mathrm{M}$ comparisons were made using Kruskal-Wallis test followed by the Student-Newman-Keuls post hoc test $(* p<0.05$ vs. Control)

versus $100 \pm 0.6 \%$ in the control cells. Considering these differences, the ATP-synthase activity was also evaluated in MTX-treated cells after $96 \mathrm{~h}$ incubation. As shown in Fig. 6c, after $96 \mathrm{~h}$ incubation with MTX (100 nM and $1 \mu \mathrm{M})$, the ATP-synthase activity was dramatically decreased $(6.8 \pm 3.8 \mathrm{nmol} \mathrm{Pi} / \mathrm{mg} / \mathrm{min}$ and $5.1 \pm 1.5 \mathrm{nmol}$ $\mathrm{Pi} / \mathrm{mg} / \mathrm{min}$, respectively) compared to control cells (18.2 $\pm 4.4 \mathrm{nmol} \mathrm{Pi} / \mathrm{mg} / \mathrm{min})$.

After incubation with MTX for 24, 48, and $96 \mathrm{~h}$, the mitochondrial membrane potential and the calcium intracellular levels were evaluated using the TMRM and the Fluo-3 AM fluorescent probes, respectively. As shown in the Fig. 7a, after $24 \mathrm{~h}$ incubation period, there was an accumulation of the TMRM probe only with the lower concentration tested $(100 \mathrm{nM})(60 \pm 11.9$ mean FI), compared to control ( $48 \pm 10.6$ mean FI). The incubation with MTX $1 \mu \mathrm{M}$ did not cause significant changes (43 \pm 13.3 mean FI) compared to control values. At the same time point, the change in the mitochondrial 
Fig. 6 a Representative western blot gel of ATPsynthase expression in the $\mathrm{H} 9 \mathrm{c} 2$ cells after $96 \mathrm{~h}$ incubation with MTX (100 nM and $1 \mu \mathrm{M})$.

Actin was used as a loading control. On b, a graphic representation of the ATPsynthase expression is presented. Results are normalized to the actin content and are presented as mean $\pm \mathrm{SD}(n=3$ independent experiments). c ATP-synthase activity in the $\mathrm{H} 9 \mathrm{c} 2$ cells after $(100 \mathrm{nM}$ and $1 \mu \mathrm{M})$. Statistical comparisons were made using Kruskal-Wallis test followed by the Student-Newman-Keuls post hoc test $(* p<0.05$ vs. Control)
(A)

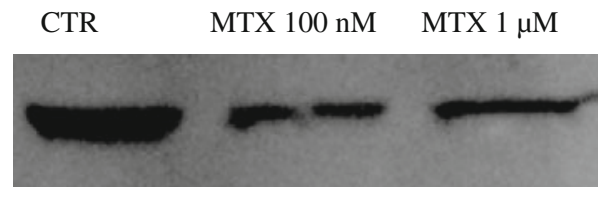

ATP-synthase

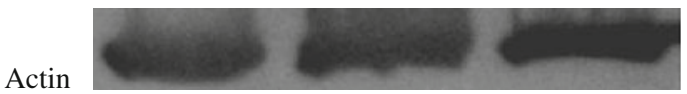
$96 \mathrm{~h}$ incubation with MTX

(B)
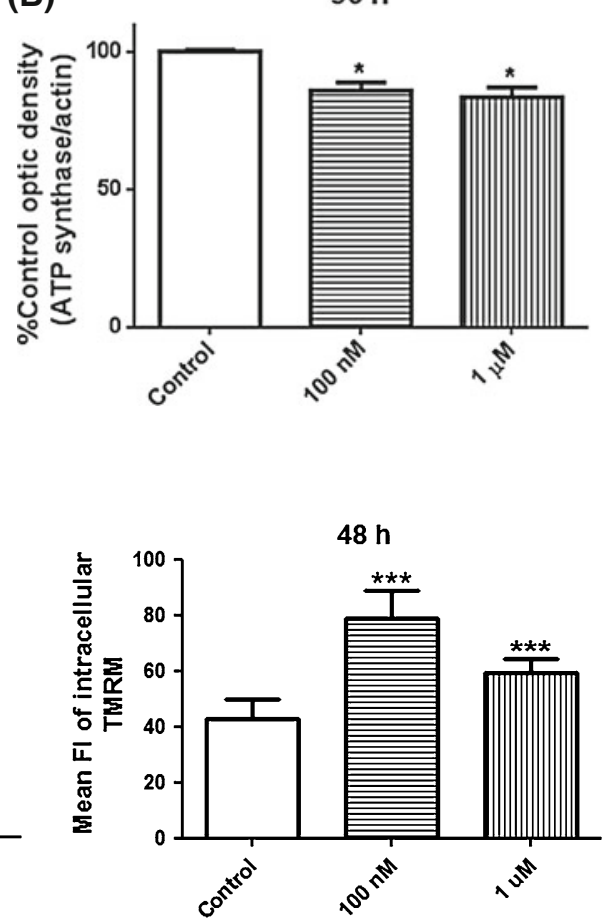

$48 \mathrm{~h}$
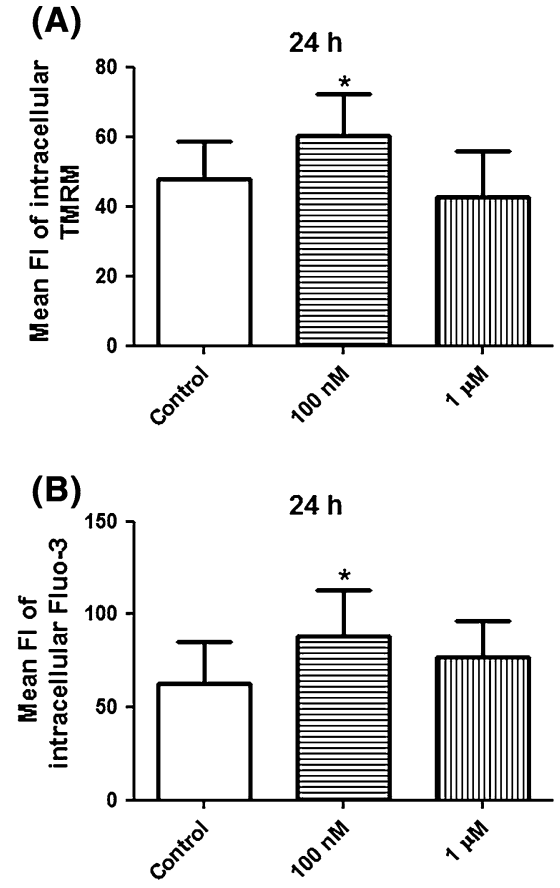

(B)

Fig. 7 a Mitochondrial membrane potential values and $\mathbf{b}$ intracellular calcium levels in the H9c2 cells after incubation with MTX (100 nM and $1 \mu \mathrm{M}$ ) for 24,48 , and $96 \mathrm{~h}$. Results are presented as mean $\pm \mathrm{SD}$ ( $n=3$ independent experiments). Statistical comparison were made

membrane potential was accompanied by a significant increase in the intracellular calcium levels only in the MTX $100 \mathrm{nM}$ group $(88 \pm 25.3$ mean FI), compared to MTX $1 \mu \mathrm{M}(77 \pm 19.3$ mean FI) and control group $(63 \pm 22.6$ mean FI) (Fig. 7b). However, after 48 h, both concentrations tested caused a dramatic hyperpolarization of the mitochondrial membrane potential $(79 \pm 10.0$ mean FI for
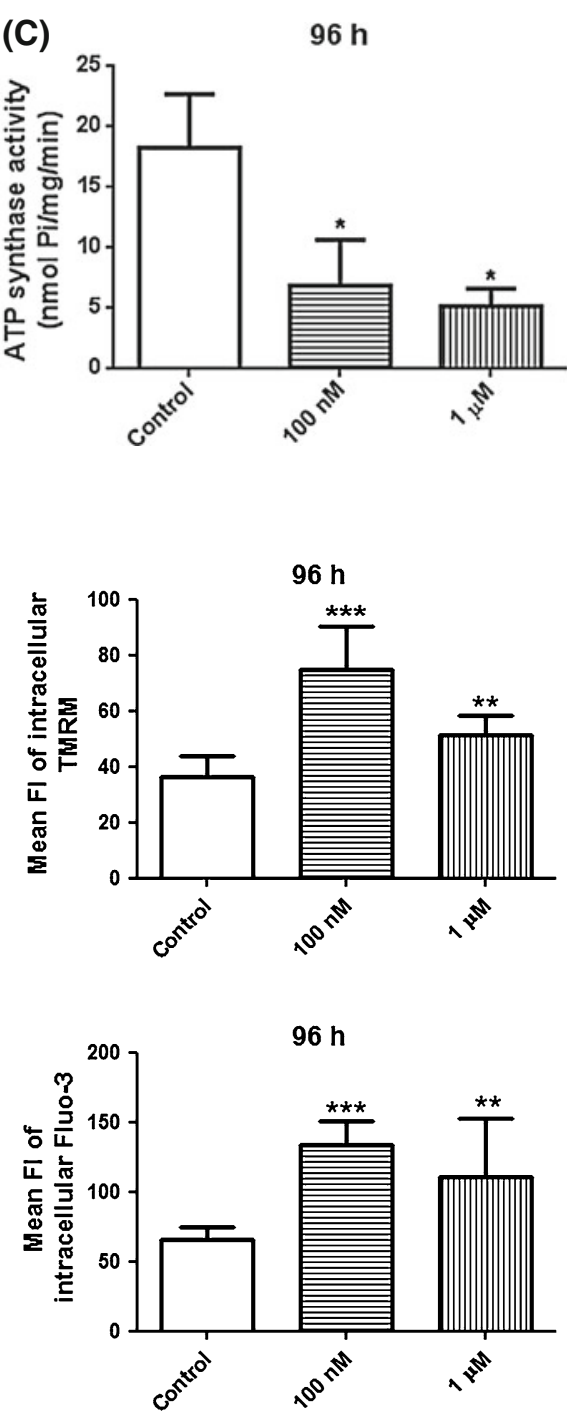

using Kruskal-Wallis test followed by the Student-Newman-Keuls post hoc test $\left(* p<0.05\right.$ vs. Control, $*^{*} p<0.01$ vs. Control, $* * * p<0.001$ vs. Control)

MTX $100 \mathrm{nM}$ group and $59 \pm 5.2$ mean FI for MTX $1 \mu \mathrm{M}$ group, compared to $43 \pm 7.1$ mean FI for control cells) (Fig. 7a) and increases in the intracellular calcium levels $(56 \pm 9.7$ mean FI for MTX $100 \mathrm{nM}$ group, $62 \pm 7.7$ mean FI for MTX $1 \mu \mathrm{M}$ vs. $40 \pm 3.6$ mean FI for control cells) (Fig. 7b). At the last time tested (96 h), the mitochondrial membrane potential did not recover to control 
values, keeping the same trend observed earlier $(75 \pm 15.8$ mean FI for MTX $100 \mathrm{nM}$ group, $51 \pm 7.0$ mean FI for MTX $1 \mu \mathrm{M}$ group vs. $36 \pm 7.6$ mean FI for control cells). Conversely, the calcium intracellular levels of treated cells remained higher than control cells (134 \pm 16.4 mean FI for MTX $100 \mathrm{nM}$ group, $111 \pm 41.8$ mean FI for MTX $1 \mu \mathrm{M}$ group vs. $66 \pm 8.8$ mean FI for control cells) (Fig. 7b).

\section{Discussion}

In the present work, we showed a time- and concentrationdependent response to MTX incubation in $\mathrm{H} 9 \mathrm{c} 2$ cells, through two different cytotoxicity tests (LDH leakage assay and MTT reduction test, Figs. 1 and 2, respectively). We also contributed to the elucidation of the mechanisms involved in MTX cellular injury. Our results suggest an important energetic crisis caused by MTX evidenced by substantial and early decreases in the ATP intracellular levels, late inhibition of the ATP-synthase expression and activity, hyperpolarization of the mitochondrial membrane potential, and increase in the intracellular calcium levels. Another $24 \mathrm{~h}$ event elicited by MTX was the increase in the caspase- 3 activity, while in our model, oxidative stress markers were only changed at the longest incubation time tested.

As already stated, by using several MTX concentrations, we observed a time- and concentration-dependent cytotoxicity pattern in both cytotoxicity tests used, being the toxic effects observed earlier in the MTT reduction assay than in the LDH leakage assay in all times tested (Figs. 1, 2 ). These results suggest that mitochondrial effects anticipate cellular membrane rupture in the MTX toxicity.

For studying the mechanisms of MTX cardiotoxicity, we have selected 2 working concentrations: $100 \mathrm{nM}$ and $1 \mu \mathrm{M}$. Indeed, both MTX concentrations are clinically relevant given the plasma and tissue levels of MTX found in the literature $[6,27]$. In fact, the mean maximum plasma concentrations in humans after a $15 \mathrm{mg} / \mathrm{m}^{2}$ or a $90 \mathrm{mg} / \mathrm{m}^{2}$ 30-min infusion of MTX are about 1.5 and $12 \mu \mathrm{M}$, respectively [27]. For the caspase-3 activity assay, the incubation period of $24 \mathrm{~h}$ was selected due to the measurable decreases in the cytotoxicity observed in the reduction of MTT test at this time point in both working concentrations (indicating mitochondrial damage) (Fig. 2) and the absence of significant decreases in the LDH leakage in the same conditions (indicative of necrosis). In fact, after $24 \mathrm{~h}$ incubation, despite the absence of significant loss of viability seen on the LDH leakage assay, both chosen MTX concentrations caused activation of caspase-3 (Fig. 3), which was in accordance with the described bimodal mechanism of cell death induced by MTX: apoptosis at lower concentrations and necrosis at higher concentrations
[28]. Similar signals of apoptosis were already described after 24 and $48 \mathrm{~h}$ of MTX $(1.60 \mu \mathrm{M})$ incubation in the H9c2 cells [29]. Noteworthy, the late effects of MTX in the human heart are more related with loss of functionality of the cells rather than necrosis and lysis.

We recently demonstrated a partial protection toward MTX cytotoxicity (100 $\mathrm{nM}$ and $1 \mu \mathrm{M})$ in the same cellular model after $96 \mathrm{~h}$, with the co-incubation with the CYP450 inhibitor metyrapone $(0.5 \mathrm{mM})$ or with the CYP2E1 inhibitor diallyl sulfide $(150 \mu \mathrm{M})$ [14]. However, in the present study, the co-incubation with these metabolism inhibitors did not prevent the increase in the caspase- 3 activity. Altogether, these results suggest that the previous partial protection obtained with the metabolism inhibitors is not related to this caspase-dependent activation. In fact, that protective effect occurred at a late incubation time, and as we can observe in the present work, the features of MTX cytotoxicity are rather dissimilar in the time course.

Oxidative stress is described as a possible cellular mechanism involved in MTX cardiotoxicity, as an attempt to reveal similarities to the cardiotoxicity caused by doxorubicin [13]. In fact, MTX contains a quinone group within its chemical structure that can potentially suffer oxidative activation leading to reactive species generation $[12,13]$. Both probes employed in the present study are non-fluorescent that undergo intracellular oxidation to their respective fluorescent products in the presence of reactive species such as peroxynitrite, hydroxyl radical, and superoxide. However, herein, we did not find any strong evidence of reactive species involvement in earlier MTX cytotoxicity for $100 \mathrm{nM}$ and $1 \mu \mathrm{M}$ concentrations. In fact, until $10 \mathrm{~h}$ of incubation, no free radical (peroxynitrite, hydroxyl radical, or superoxide) generation was observed by using two different probes, DHR and DCFH-DA. In accordance, only a very low superoxide anion generation was described in MCF-7 S9 fractions after incubation with MTX $100 \mu \mathrm{M}$ for $30 \mathrm{~min}$, with no hydroxyl radical or semiquinone formation even for $400 \mu \mathrm{M}$ MTX [30]. These results can eventually explain the absence of any lipid peroxidation or changes in GSHt, GSH, and GSSG intracellular levels observed by us, at 24 and $48 \mathrm{~h}$ MTX incubation. After $96 \mathrm{~h}$ MTX incubation, a slight decrease in intracellular GSH for $100 \mathrm{nM}$ MTX (Fig. 4c), a reduction in GSHt levels (Fig. 4b), and no significant changes in GSSG and lipid peroxidation were observed. Noteworthy, we also found a reactive species generation for $100 \mathrm{nM}$ and $1 \mu \mathrm{M}$ MTX at this late time point (Fig. 4a), which is in accordance with the previous observation that peroxides production occurs only after a prolonged incubation with MTX $(1.60 \mu \mathrm{M})$ in the H9c2 cells [29]. However, no changes in intracellular GSH content were observed for $1 \mu \mathrm{M}$ of MTX: this probably results in some adaptive and early phenomenon. In fact, oxidative alterations seem to 
occur quite late. One possible explanation is that MTX has a reduced ability to enter in redox cycle and, consequently, to produce reactive species in a enzymatic catalyzed fashion as its congener doxorubicin, while the preferential metabolic pathway of MTX is two-electron reduction rather than one-electron reduction [13, 30]. Nevertheless, we tested NAC in our experimental conditions. Consistently, the co-incubation with the radical scavenger NAC $(1 \mathrm{mM})$ did not prevent any of the cytotoxic effects observed with the MTX (100 nM and $1 \mu \mathrm{M})$ incubation for $96 \mathrm{~h}$ in the MTT reduction test. However, in vivo and in vitro protective studies using NAC have demonstrated the efficacy of NAC in reversing the drug-induced cardiomyopathy related to oxidative stress [20, 31, 32]. The use of NAC is based on its antioxidant properties and actions upon the GSH pathways; thus, the lack of protective effects of NAC in the present study may result in the fact that other mechanisms involved in MTX toxicity exert a major role when compared to oxidative stress. Conversely, the observed absence of lipid peroxidation is in accordance with the results obtained in heart homogenates from MTX-treated mice (15 mg/kg, i.p.) [33]. Noteworthy, the inhibition of lipid peroxidation was already associated with MTX in in vitro incubations. In liver microsomes, heart sarcosomes, and mitochondria isolated from rabbit incubated with MTX $(50,100$, and $200 \mu \mathrm{M})$, the levels of lipid peroxidation were significantly lower than those observed in controls [34]. These inhibitory effects in lipid peroxidation still remain unclear, but MTX was described as having some antioxidant properties [34].

The major finding presented herein is the energetic imbalance observed in the cells after incubation with MTX (100 $\mathrm{nM}$ and $1 \mu \mathrm{M}$ ). Despite the low MTX concentrations used, the cellular ATP content decreased around $50 \%$ in all time tested $(24,48$, and $96 \mathrm{~h}$ ) (Fig. 5). It is known that $\mathrm{H} 9 \mathrm{c} 2$ is a cellular model that privileges the glycolytic pathway, and MTX seems to interfere with this pathway. This early ATP crisis could precipitate fatal changes in the cell. This event can lead to a less efficient calcium control and mitochondrial electron chain regulation, as we can see with the increase in intracellular calcium content and the hyperpolarization of the mitochondrial membrane potential (Fig. 7). The mitochondrial hyperpolarization should drive more calcium into the mitochondria matrix and impair electron chain mitochondrial activity, as we can indirectly observe in the MTT reduction test and ATP-synthase activity. The mitochondrial membrane potential may also be elevated as an attempt to provide motive force to restore the energetic homeostasis. The increase in the mitochondrial membrane potential was also observed in pathological conditions in ischemic cardiomyocytes during reperfusion [35], in vascular endothelial cells after pulsatile shear stress [36], and physiologically during preimplantation stages of human and mouse embryo development, in response to metabolic demand [37]. On the other hand and in contrast to our present work, the incubation of $1.60 \mu \mathrm{M}$ MTX for $24 \mathrm{~h}$ with the H9c2 cells was enough to cause a drop in the mitochondrial membrane potential [29], while in our lower concentrations, a hyperpolarization was observed. Considering the energetic failure, $L$-carnitine was used by us to study a possible protection to MTX effects. $L$-carnitine $(1 \mathrm{mM})$ is considered a mitochondrial enhancer by improving the mitochondrial $\beta$-oxidation of fatty acids, the trans-esterification/excretion of acyl-CoA esters, the oxidation of $\alpha$-ketoacids, and the removal of toxic acylcarnitine ester from the mitochondria, providing this metabolic pathway as a source of ATP synthesis [38, 39, 40]. $L$-carnitine was already employed in the H9c2 cell model to study the possible protection against doxorubicin [40]. However, it did not protect the H9c2 cells from the cytotoxicity induced by MTX incubation ( $96 \mathrm{~h}$ ), evaluated through the MTT reduction test. Therefore, other mechanisms must be involved in the MTX toxicity towards ATP pathways.

In our study, a decrease in ATP-synthase expression, but mostly a drastic reduction in ATP-synthase activity, was found after $96 \mathrm{~h}$ of MTX incubation (Fig. 6). These effects were not described before for MTX. The decrease in the ATP-synthase content and activity (Fig. 6) can contribute to the observed increases in the reactive species generation at late periods (Fig. 4). This late generation of reactive species possibly contributes to decrease in GSH. We evaluated early and late time points of reactive species formation (until $10 \mathrm{~h}$ and after $96 \mathrm{~h}$ ), but it is easy to assume that $1 \mu \mathrm{M}$ MTX caused the formation of reactive species after those $10 \mathrm{~h}$ and before $96 \mathrm{~h}$, allowing an adaptation feature of GSH synthesis. Noteworthy, GSH is mainly concentrated in mitochondria and functions as an internal intracellular antioxidant buffer for the most important target of oxidative stress in the heart, the mitochondria [41].

The energetic dysfunction can result in calcium regulation impairment, since the cellular mechanisms involved in calcium handling are ATP driven. Thus, at low energetic levels, calcium pumping activity decreases, resulting in cytosolic calcium increases [35]. A sustained elevation in calcium levels can, ultimately, determine the loss of mitochondrial membrane potential and trigger the cell to the "no return point," leading to cell death [42]. Moreover, the calcium increase may be responsible for the early activation of caspase-3 observed (Fig. 3). Although the effects are clear and consistent, it is still difficult to point out the cause of the initial decrease in ATP level. Noteworthy, significant decreased levels of ATP were already demonstrated $72 \mathrm{~h}$ after the $3 \mathrm{~h}$ pre-incubation of MTX (about $0.1-10 \mu \mathrm{M}$ ) in cultured neonatal rat cardiac cells 
[15], evidencing that even after cessation of that shortperiod MTX incubation, the cardiac cells were unable to recover energetic levels.

Our results suggest that the mild oxidative stress observed in our study with MTX does not seem to be related to its redox cycle being secondary to a more dramatic and earlier event: the energetic imbalance. The main results of this study are related to the energetic toxic effects, evidenced by decreases in the ATP levels, hyperpolarization of the mitochondrial membrane potential, increases in the intracellular calcium levels, and late inhibition of the ATP-synthase expression and activity, observed after MTX incubation with expected therapeutic concentrations. It is well known that changes in cardiac energetics can lead to a heart failure condition. Thus, the results presented here contribute to the elucidation of mechanisms involved in the cardiotoxicity of MTX.

Acknowledgments This work received financial support from "Fundação para a Ciência e Tecnologia (FCT)," Portugal (EXPL/ DTP-FTO/0290/2012) and by "Fundo Comunitário Europeu" (FEDER) under the frame of "Eixo I do Programa Operacional Fatores de Competitividade (POFC) do QREN" (COMPETE: FCOMP01-0124-FEDER-027749). The work was also supported by FCT within the framework of Strategic Projects for Scientific Research Units of R\&D (project PEst-C/EQB/LA0006/2011). LGR and VVB thank FCT for their PhD Grant (SFRH/BD/63473/2009 and SFRH/ BD/82556/2011, respectively) and VMC thank FCT for her Post-doc Grant (SFRH/BPD/63746/2009). Authors are grateful to Dr. Vilma Sardão, from University of Coimbra, for gently providing us with the cellular model used in this work.

\section{References}

1. Seiter, K. (2005). Toxicity of the topoisomerase II inhibitors. Expert Opinion on Drug Safety, 4, 219-234.

2. Kingwell, E., Koch, M., Leung, B., Isserow, S., Geddes, J., Rieckmann, P., et al. (2010). Cardiotoxicity and other adverse events associated with mitoxantrone treatment for MS. Neurology, 74, 1822-1826.

3. Khan, S. N., Lai, S. K., Kumar, P., \& Khan, A. U. (2010). Effect of mitoxantrone on proliferation dynamics and cell cycle progression. Bioscience Reports, 30, 375-381.

4. Hajihassan, Z., \& Rabbani-Chadegani, A. (2011). Interaction of mitoxantrone, as an anticancer drug, with chromatin proteins, core histones and $\mathrm{H} 1$, in solution. International Journal of Biological Macromolecules, 48, 87-92.

5. Alderton, P. M., Gross, J., \& Green, M. D. (1992). Comparative study of doxorubicin, mitoxantrone, and epirubicin in combination with ICRF-187 (ADR-529) in a chronic cardiotoxicity animal model. Cancer Research, 52, 194-201.

6. Batra, V. K., Morrison, J. A., Woodward, D. L., Siverd, N. S., \& Yacobi, A. (1986). Pharmacokinetics of mitoxantrone in man and laboratory animals. Drug Metabolism Reviews, 17, 311-329.

7. Sereno, M., Brunello, A., Chiappori, A., Barriuso, J., Casado, E., Belda, C., et al. (2008). Cardiac toxicity: Old and new issues in anti-cancer drugs. Clinical and Translational Oncology, 10, 35-46.

8. Wallace, K. B. (2003). Doxorubicin-induced cardiac mitochondrionopathy. Pharmacology and Toxicology, 93, 105-115.
9. Brück, T. B., \& Brück, D. W. (2011). Oxidative metabolism of the anti-cancer agent mitoxantrone by horseradish, lacto-and lignin peroxidase. Biochimie, 93, 217-226.

10. Duthie, S. J., \& Grant, M. H. (1989). The role of reductive and oxidative metabolism in the toxicity of mitoxantrone, adriamycin and menadione in human liver derived Hep G2 hepatoma cells. British Journal of Cancer, 60, 566-571.

11. Panousis, C., Kettle, A., \& Phillips, D. R. (1995). Myeloperoxidase oxidises mitoxantrone to metabolites which bind covalently DNA and RNA. Anticancer drug designer, 10, 593-605.

12. Mewes, K., Blanz, J., Ehninger, G., Gebhardt, R., \& Zeller, K. P. (1993). Cytochrome P-450-induced cytotoxicity of mitoxantrone by formation of electrophilic intermediates. Cancer Research, 53, 5135-5142.

13. Li, S. J., Rodgers, E. H., \& Grant, M. H. (1995). The activity of xenobiotic enzymes and the cytotoxicity of mitoxantrone in MCF 7 human breast cancer cells treated with inducing agents. Chemico Biological Interactions, 97, 101-118.

14. Rossato, L., Costa, V., De Pinho, P., Freitas, V., Viloune, L., Bastos, M., et al. (2013). The metabolic profile of mitoxantrone and its relation with mitoxantrone-induced cardiotoxicity. Archives of Toxicology. doi:10.1007/s00204-013-1040-6.

15. Shipp, N. G., Dorr, R. T., Alberts, D. S., Dawson, B. V., \& Hendrix, M. (1993). Characterization of experimental mitoxantrone cardiotoxicity and its partial inhibition by ICRF-187 in cultured neonatal rat heart cells. Cancer Research, 53, 550-556.

16. Bachmann, E., Weber, E., \& Zbinden, G. (1987). Effect of mitoxantrone and doxorubicin on energy metabolism of the rat heart. Cancer Treatment Reports, 71, 361-366.

17. Kimes, B. W., \& Brandt, B. L. (1976). Properties of a clonal muscle from rat heart. Experimental Cell Research, 98, 367-381.

18. Zordoky, B. N. M., \& El-Kadi, A. O. S. (2007). H9c2 cell line is a valuable in vitro model to study the drug metabolizing enzymes in the heart. Journal of Pharmacological and Toxicological Methods, 56, 317-322.

19. Costa, V. M., Silva, R., Ferreira, R., Amado, F., Carvalho, F., Bastos, M. L., et al. (2009). Adrenaline in pro-oxidant conditions elicits intracellular survival pathways in isolated rat cardiomyocytes. Toxicology, 257, 70-79.

20. Rossato, L. G., Costa, V. M., De Pinho, P. G., Carvalho, F., Bastos, M. L., \& Remião, F. (2011). Structural isomerization of synephrine influences its uptake and ensuing glutathione depletion in rat-isolated cardiomyocytes. Archives of Toxicology, 85, 929-939.

21. Sayed-Ahmed, M. M., Shaarawy, S., Shouman, S. A., \& Osman, A. M. (1999). Reversal of doxorubicin-induced cardiac metabolic damage by L-carnitine. Pharmacological Research, 39, 289-295.

22. Angeloni, C., Spencer, J. P. E., Leoncini, E., Biagi, P. L., \& Hrelia, S. (2007). Role of quercetin and its in vivo metabolites in protecting H9c2 cells against oxidative stress. Biochimie, 89, 73-82.

23. Grotto, D., Santa Maria, L. D., Boeira, S., Valentini, J., Charão, M. F., Moro, A. M., et al. (2007). Rapid quantification of malondialdehyde in plasma by high performance liquid chromatography-visible detection. Journal of Pharmaceutical and Biomedical Analysis, 43, 619-624.

24. Costa, V. M., Silva, R., Ferreira, L. M., Branco, P. S., Carvalho, F., Bastos, M. L., et al. (2007). Oxidation process of adrenaline in freshly isolated rat cardiomyocytes: Formation of adrenochrome, quinoproteins, and GSH adduct. Chemical Research in Toxicology, 20, 1183-1191.

25. Floryk, D., \& Houstěk, J. (1999). Tetramethyl rhodamine methyl ester (TMRM) is suitable for cytofluorometric measurements of mitochondrial membrane potential in cells treated with digitonin. Bioscience Reports, 19, 27-34.

26. Carvalho, M., Remião, F., Milhazes, N., Borges, F., Fernandes, E., Monteiro, M. D. C., et al. (2004). Metabolism is required for 
the expression of ecstasy-induced cardiotoxicity in vitro. Chemical Research in Toxicology, 17, 623-632.

27. Canal, P., Attal, M., Chatelut, E., Guichard, S., Huguet, F., Muller, C., et al. (1993). Plasma and cellular pharmacokinetics of mitoxantrone in high-dose chemotherapeutic regimen for refractory lymphomas. Cancer Research, 53, 4850-4854.

28. Neuhaus, O., Kieseier, B. C., \& Hartung, H.-P. (2006). Therapeutic role of mitoxantrone in multiple sclerosis. Pharmacology \& Therapeutics, 109, 198-209.

29. Kluza, J., Marchetti, P., Gallego, M.-A., Lancel, S., Fournier, C., Loyens, A., et al. (2004). Mitochondrial proliferation during apoptosis induced by anticancer agents: Effects of doxorubicin and mitoxantrone on cancer and cardiac cells. Oncogene, 23, 7018-7030.

30. Fisher, G. R., \& Patterson, L. H. (1992). Lack of involvement of reactive oxygen in the cytotoxicity of mitoxantrone, CI941 and ametantrone in MCF-7 cells: comparison with doxorubicin. Cancer Chemotherapy and Pharmacology, 30, 451-458.

31. Chen, F., Lewis, W., Hollander, J. M., Baseler, W., \& Finkel, M. S. (2012). $N$-acetylcysteine reverses cardiac myocyte dysfunction in HIV-Tat proteinopathy. Journal of Applied Physiology, 113, 105-113.

32. Chen, F., Hadfield, J., Berzingi, C., Hollander, J., Miller, D., Nichols, C., et al. (2013). $N$-acetylcysteine reverses cardiac myocyte dysfunction in a rodent model of behavioral stress. Journal of Applied Physiology, 115, 514-524.

33. Arnaiz, S. L., \& Llesuy, S. (1993). Oxidative stress in mouse heart by antitumoral drugs: A comparative study of doxorubicin and mitoxantrone. Toxicology, 77, 31-38.
34. Novak, R. F., \& Kharasch, E. D. (1985). Mitoxantrone: Propensity for free radical formation and lipid peroxidation-implications for cardiotoxicity. Investigational New Drugs, 3, 95-99.

35. Dong, Z., Saikumar, P., Weinberg, J. M., \& Venkatachalam, M. A. (2006). Calcium in cell injury and death. Annual Review of Pathology: Mechanisms of Disease, 1, 405-434.

36. Li, R., Beebe, T., Cui, J., Rouhanizadeh, M., Ai, L., Wang, P., et al. (2009). Pulsatile shear stress increased mitochondrial membrane potential: Implication of Mn-SOD. Biochemical and Biophysical Research Communications, 388, 406-412.

37. Acton, B. M. (2004). Alterations in mitochondrial membrane potential during preimplantation stages of mouse and human embryo development. Molecular Human Reproduction, 10, 23-32.

38. Zammit, V. A., Ramsay, R. R., Bonomini, M., \& Arduini, A. (2009). Carnitine, mitochondrial function and therapy. Advanced Drug Delivery Reviews, 61, 1353-1362.

39. Mijares, A., \& López, J. R. (2001). L-carnitine prevents increase in diastolic $\left[\mathrm{Ca}^{2+}\right]$ induced by doxorubicin in cardiac cells. European Journal of Pharmacology, 425, 117-120.

40. Newman, R., Hacker, M., \& Krakoff, I. (1981). Amelioration of adriamycin and daunorubicin myocardial toxicity by adenosine. Cancer Research, 41, 3483-3488.

41. Costa, V. M., Carvalho, F., Bastos, M. L., Carvalho, R. A., Carvalho, M., \& Remião, F. (2011). Contribution of catecholamine reactive intermediates and oxidative stress to the pathologic features of heart diseases. Current Medical Chemistry, $18,2272-2314$.

42. Trump, B. F., \& Berezesky, I. K. (1995). Calcium-mediated cell injury and cell death. FASEB, 9, 219-228. 